\title{
INMIGRACIÓN DE AGRICULTORES ESPAÑOLES A LA REPÚBLICA DOMINICANA EN EL PERÍODO FRANCO-TRUJILLO (1939-1961)
}

\author{
POR \\ FRANCIS POU \\ Fundación García-Arevalo \\ Santo Domingo
}

\section{ANTECEDENTES}

En el caso que nos ocupa, la historia de la emigración de españoles agricultores hacia estas tierras se remonta a los albores de la Conquista, ya que entre los 1.500 hombres que acompañaban a Cristóbal Colón, en su segundo viaje, según expresara Fray Bartolomé de las Casas, llegaron: «mucha parte de gente trabajadora del campo para trabajar, arar y cavar» (1). De la misma manera, en un memorial de 1495, relativo al envío de cuatro embarcaciones que pasarían a las Indias, aparecen en la lista "diez o doce labradores", lo mismo que «arroz e mijo para sembrar, y hortelanos que vendan lo que hobiese de las huertas al precio que les fuere puesto" (2). Posteriormente, por disposición de la real cédula fechada en 23 de abril de 1497 se embarcan hacia La Española 330 personas, entre las cuales había «50 labradores del campon, ordenándosele al Almirante que en La Isabela y en la población que después se fundara, "se hiciese alguna labranza y crianza para que mejor se mantuviese la gente que aquí estuviese, para lo cual se habían de prestar a los labradores 50 fanegas de trigo para que lo sembrasen, y a la cosecha, lo volviesen y pagaren el diezmo a Dios; de lo demás se aprovecha-

Sigla UTII.IZADA:

MEAE: Ministerio Español de Asuntos Exteriores. Madrid.

(1) Fray Bartolome de las Casas, Historia de las Indias. Edición de Agustín Millares Carlo, México, Fondo de Cultura Económica, 1965, tomo I, pág. 346.

(2) Manuel Firnánid:z de Navarrete, Colección de viajés y descubrimientos que hicieron por mar los españoles desde fines del siglo XV. Madrid, Biblioteca de Autores Españoles, 1954, tomo I, pág. 399. 
sen, vendiéndolo a los vecinos y gentes que acá estuviese al precio razonable; para esto le mandaron librar en las tierras del arzobispado de Sevilla 600 calices de trigo" (3). La ordenanza real también contemplaba que: «entretanto que se hacían molinos y atohonas para moler el trigo que traía [el Almirante], y el que se esperaba que daria la tierra; lo mismo se le mandó que sobre las vacas y yeguas que había en esta isla trajiese para cumplimiento de 20 juntas de vacas y yeguas y asnos, para poder labrar los labradores la tierra» (4).

Los primeros colonos agrícolas desconocían las características del clima tropical por lo que se encontraron con serias dificultades para proveerse de alimentos, quedando el sustento de estos europeos a expensas del abastecimiento que suministraba la población indígena, la cual fue sometida, empleándose para la obtención de bienes y servicios. Luego de un período de auge, durante las primeras décadas del siglo XVI, en que Santo Domingo fue "llave, puerto y escala de todas las Indias», la colonia comienza a despoblarse, debido a la acentuada declinación demográfica de los aborígenes antillanos y al desplazamiento de la población hispana tras mejores posibilidades de obtención de riquezas que ofrecían los vastos territorios continentales. De este modo, durante los siglos XVII y XVIII, múltiples fueron los reclamos de las autoridades insulares, para que la Corona autorizara el traslado de agricultores españoles, con la finalidad de repoblar e incrementar la producción agrícola de la isla Española. Como resultado de esta política de tipo poblacionista, a partir de entonces, ingresan a la colonia de Santo Domingo numerosos contingentes procedentes del archipiélago canario, cuyas aportaciones se han dejado sentir hasta la actualidad en el ámbito demográfico, económico y cultural de nuestro país.

La primera inmigración canaria se asentó a finales del siglo XVII, en las cercanías de la ciudad de Santo Domingo, fundando la villa denominada Villanueva de San Carlos de Tenerife o Villa de los Isleños, grupo que se dedicó a la labranza de la tierra y abasteció de víveres a la población de la capital (5).

Los perturbadores acontecimientos políticos y administrativos que, a partir de finales del siglo XVIII sacudieron y estremecieron a la colonia, retardaron el trasiego y las acciones emprendidas por los agricultores españoles. Máxime desde el Tratado de Basilea,

(3) Las CASAS [1], I, pág. 436.

(4) Idem, ibidem.

(5) Emilio Rodríguez Demorizi (Ed.). Relaciones históricas de Santo Domingo. Santo Domingo 1957, III, pág. 310-315. 
firmado el 22 de julio de 1795, en que España cedió completamente su dominio sobre la isla de Santo Domingo. A principios de 1801, el jefe revolucionario de ascendencia africana, Toussaint L'Ouverture invadió la parte oriental y llegó a la ciudad de Santo Domingo, unificando ambas partes de la isla bajo el dominio francés que él representaba. Tales acontecimientos provocaron un éxodo masivo de familias españolas y criollas hacia Cuba y preferiblemente a Puerto Rico y Venezuela, en especial a Caracas y Maracaibo.

En la «Era de Francia en Santo Domingo», como se ha llamado a este período que duró de 1801 al 1808, el general Juan Sánchez Ramírez derrotó a los franceses en la Batalla de Palo Hincado y con el apoyo de tropas españolas, enviadas desde Puerto Rico y la ayuda de la marina británica, logró el control absoluto de la antigua colonia, que por voluntad propia de sus pobladores volvió a ser posesión de la metrópoli, en un acto de identificación con España que tiene pocos antecedentes en la historia americana de la época contemporánea. Sin embargo, en 1822, durante el gobierno de Nuñez de Cáceres, Haití, que había proclamado su independencia desde 1804, invadió la parte este de la isla, dando paso a una dominación que duraría veintidós años.

A pesar de haberse proclamado la independencia dominicana en 1844, las posteriores y constantes amenazas de invasiones haitianas y la inestabilidad política que prevalecía entonces, impedían la existencia de condiciones adecuadas para que se establecieran agricultores extranjeros en el país. Bajo tales condiciones, no es hasta el umbral de la Anexión a España, efectuada en 1861, cuando estos planes poblacionistas, de tipo inmigracionistas, son contemplados nuevamente. En efecto, como expresión de un sentimiento proclive a la presencia hispana en suelo dominicano, tuvo lugar una inmigración canaria y gallega, facilitando los asentamientos en la zona rural, con adjudicaciones de tierras y mantenimiento en metálico hasta que obtuviesen sus propias cosechas. Navegando tanto en buques de la Armada Española como en veleros de la flota dominicana y extranjera - "Rosa», «Nueva Ex», "Manuela», "Separación», "Amalia», "Pilgrin», "27 de Febrero" y otros-, llegaron a puertos dominicanos centenares de canarios, la mayor parte de ellos refugiados de las luchas internas proindependentistas en Venezuela, quienes solos o en compañía de sus familiares salían para proteger sus vidas (6). Igualmente, inmigrantes gallegos, vía Puerto Rico y Cuba, se embarcan en el

(6) Roberto MARTE, Cuba y la República Dominicana, transición económica en el Caribe del siglo XIX. Santo Domingo, Universidad de Santo Domingo, 1988, págs. 156-159. 
buque "El Ferrol», junto a cierto número de catalanes, para establecerse en suelo dominicano, no solo como colonos agrícolas sino también como inversionistas.

De acuerdo a fuentes documentales de finales del siglo pasado, el Estado Dominicano concertó sendos contratos con los empresarios de inmigración española, Manuel Pereira y Andrés Sosvilla y González, en 1860 y 1884, respectivamente, para traer familias canarias hacia las provincias de Samaná y Puerto Plata (7).

Como expresión de la importancia que para esos años se le asignaba al ingreso de pobladores españoles en Santo Domingo, en 1885, el intelectual antillanista Eugenio María de Hostos escribió el artículo Centro de inmigración y colonias agrícolas publicado en un diario de la época. En el mismo hacía especial énfasis en la inmigración como un medio de desarrollo económico, argumentando que a través de ella se captarían "familias organizadas y agentes de trabajo agrícolas e industriales», además de sus contribuciones en los aspectos ideológicos de la educación, la ciencia, la política, etc. Para Hostos, el establecimiento de colonias agrícolas en "terrenos apropiados y apropiables serviría como ejemplo económico, doméstico y cívico de la población». Igualmente, este prominente intelectual enfático en que "se coloniza para cultivar a la par el suelo y el hombre» (8).

\subsection{La inmigración durante el primer tercio del siglo $X X$}

Durante el período constitutivo del Estado dominicano, y después de la ocupación norteamericana (1916-1924), la inmigración -principalmente la española-, asumió un papel significativo en términos de políticas poblacionistas a definir y ejecutar; como lo testimonian las diversas opiniones externadas tanto por sectores privados, a través de artículos y editoriales, como mediante la promulgación de leyes y decretos para regularlas. En el editorial del diario La Opinión, del 3 de enero de 1928, titulado "Ley de inmigración", se instaba al Congreso a la reforma de dicha ley, como medio para fomentar la entrada de agricultores:

«Las primeras demostraciones de laboriosidad legislativa que debe dar nuestro Congreso al iniciar sus trabajos, debe ser la

(7) Leyes de 1884, en Colección de Leves y Decretos de la Repliblica Dominicana, Santo Domingo, 1954, págs. 243-347. También José del CAstill.o, Ensayos de' Sociología Dominicana. Santo Domingo, 1981, pág. 164.

(8) Eugenio María de Hostos en Eco de la opinión, 1882. 
reforma de la Ley de Inmigración en una forma amplia $y$ cientifica que estimule el feliz arribo de fuertes corrientes de inmigración de agricultores, que ya con sus recursos propios o con lo que les of rezcan los capitalistas nacionales o extranjeros radicados en el país, vengan a buena hora a impulsar el iniciado auge de la agricultura hasta convertirla en fuente rica y pródiga de Progreso Nacional».

Dentro de estos esfuerzos legislativos y otras medidas seguidas para alcanzar tal propósito, se favoreció la emigración caucásica $y$, en especial, la española, por los beneficios que significaba «la estirpe de la raza" - tal y como fielmente expresa la documentación de la época-, así como por la identidad cultural entre el ámbito hispano y el dominicano. En 1927 se registran ya los primeros asentamientos de inmigrantes blancos en seis colonias experimentales agrícolas en el Noroeste y Suroeste del territorio dominicano, en las provincias de Monte Cristy, Azua y Barahona.

\subsection{La inmigración de republicanos españoles}

A raíz de la toma del poder por parte de Trujillo en 1930, tuvo lugar la promulgación de una serie de modificaciones a las leyes de inmigración, como parte del interés del régimen por incrementar el volumen de la población; establecer una supremacía de población blanca frente al progresivo incremento de la negra, especialmente en las zonas fronterizas; así como propiciar el auge de la economía agrícola, mediante asentamientos en colonias ubicadas en zonas rurales.

Con motivo de la celebración de la Conferencia de Evian en 1938, promovida por el presidente norteamericano Roosevelt, en respuesta a los millones de europeos (en particular, judíos), perseguidos por los nazis y de los refugiados políticos, en referencia al caso de los emigrantes republicanos españoles, el régimen de Trujillo elaboró una propuesta,.mediante la cual la República Dominicana se of recía en calidad de país receptor para el ingreso de 50.000 a 100.000 personas. Con esta medida el régimen pretendía opacar su imagen negativa frente a la matanza de alrededor de 20.000 haitianos, llevada a cabo en 1937, al ofrecer en el plano internacional la supuesta figura de gobernante liberal y respetuoso de los derechos democráticos (9). De acuerdo al convenio establecido entonces por el gobierno dominicano, estos

(9) C. Harvey Gardiner, La politica de inmigración del dictador Trujillo. Santo Domingo, Ùniversidad Pedro Henriquez. Ureña, 1979, pág. 38. 
inmigrantes debian cultivar la tierra, una vez que los mismos recibieran un préstamo, implementos agrícolas, semillas necesarias y un predio de seis hectáreas, que no podría ser vendido en un periodo menor a los cinco años.

Gracias a este convenio ingresaron al país, aparte de unos 420 judios que fueron asentados en colonias agropecuarias en la costa noratlántica de la isla, refugiados políticos de la Guerra Civil española procedentes de puertos franceses, quienes aunque eran básicamente intelectuales, sindicalistas y gente cuyos oficios eran propiamente urbanos, no dudaron en participar en esta aventura, al ser la única vía a la que pudieron acceder, en ese entonces, para alejarse de una España en plena violencia y persecución política. De este modo, a través de los auspicios del Servicio de Evacuación de Republicanos Españoles (SERE), mediante el pago del pasaje y un subsidio de 50 dólares mensuales, llegaron al país alrededor de 3.000 a 4.000 emigrantes republicanos, en el período comprendido entre noviembre de 1939 y mayo de 1940 (10).

Los primeros grupos de estos inmigrantes se radicaron en la ciudad de Santo Domingo. Es a partir de la llegada de la tercera embarcación, cuando un poco más de mil refugiados fueron destinados hacia las colonias de la zona fronteriza (como la de Los Llanos en Dajabón), en la región cibaeña al establecerse en La Vega y apenas unos cuatro en Constanza y, finalmente, en el sur, al establecerse en Medina de San Cristóbal.

TABLA 1. ASENTAMIENTOS AGRÍCOLAS DE INMIGRANTES REPUBLICANOS 1941

\begin{tabular}{llc}
\hline Colonias Agricolas & \multicolumn{1}{c}{ Localización } & Población \\
\hline Juan Herrera & San Juan de la Maguana & 120 \\
La Cumbre & La Vega & 73 \\
Los Llanos & Dajabón & 63 \\
Pedro Sánchez & Hato Mayor & 120 \\
Constanza & Constanza & 40 \\
Medina & San Cristóbal & 31 \\
\hline
\end{tabular}

Fuente: Gardiner 1979, pág. 80.

(10) Este movimiento emigratorio hacia suelo dominicano concentró alrededor de 3.000 refugiados, constituídos principalmente por hombres y, en menor medida, por mujeres y niños. Vicente Llorens, Memorias de una emigración, Barcelona, Ariel, 1975, pág. 39. 
GeNPIC 1

\section{ASENTAMIENTOS AGRICOLAS DE INMIGRANTES REPUBLICANOS 1941}

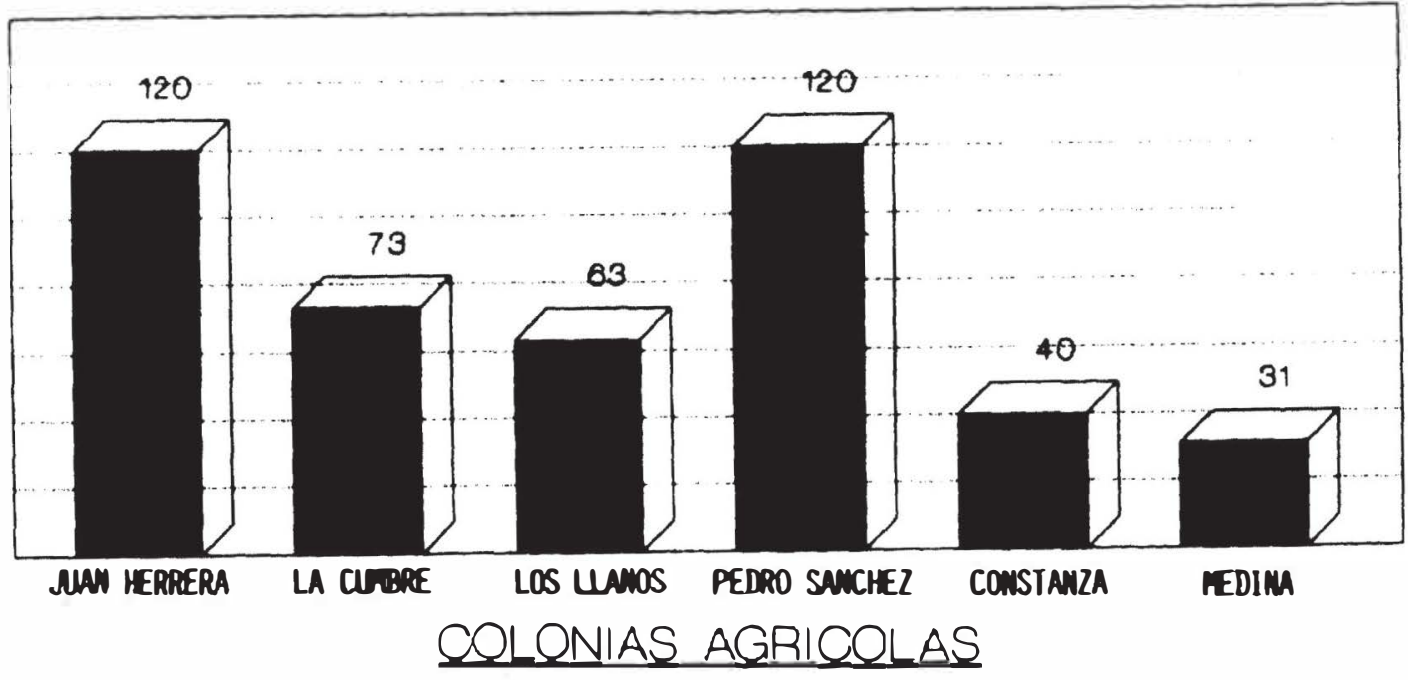

POPLACION EN CIFRAS ABSOLUTAS

GARDINES, C. HARVEY, LA POLITICA

DE INMIGRACION DEL DICTADOR TRUJILLO,

UNPHU, 1979, PAG. 80.

Estas compulsivas reubicaciones de los inmigrantes republicanos en colonias agrícolas, independientemente de sus respectivos oficios y profesiones, dio lugar a un crítico período de adaptación, puesto de manifiesto en una rápida huida de cinco de las ocho colonias agrícolas establecidas, dirigiéndose en primer lugar hacia las ciudades; mientras que tiempo más tarde, la mayor parte de los refugiados emigraron hacia otros países del continente americano, utilizando de hecho a República Dominicana como tránsito, dadas las innumerables limitaciones a las que se vieron sometidos (11). Cabe resaltar que el estado dominicano of recía precarias condiciones para el establecimiento y afianzamiento de estos inmigrantes, tanto en la zona rural como en la urbana, debido a la carencia de una infraestructura de servicios básicos (agua, luz, vías de comunicación), tecnología, asistencia

(11) Gardiner [9], pág. 84 y Llorens [10]. 
técnica, etc., e, incluso, fuentes de empleos que les permitieran obtener cierta remuneración, durante el tiempo en que la agricultura no les reportasen ingresos. Eran tales las pésimas condiciones en que se encontraban los españoles establecidos en las colonias agrícolas, que el reducido número de agricultores expertos que participaron en esta corriente migratoria, también optó por trasladarse hacia suelos ecuatorianos, animados por mejores ofrecimientos y estimulados por el Fondo de Reasentamiento del Nuevo Mundo, organización neoyorquina, establecida en ese entonces.

En estas colonias, imperaron las dificultades. En ocasiones las tierras apenas permitían el cultivo de la yuca y el plátano (Pedro Sánchez y La Cumbre), en otras, donde se sembraban arroz y maní - como eran los casos de las situadas en Dajabón y Medina-, sus pobladores se vieron fuertemente combatidos por una epidemia de malaria. En el caso de Constanza, al encontrarse asentados en un terreno pantanoso, junto a la inadaptación frente a las periódicas lluvias de la zona, impidieron la obtención de las cosechas, así como su transporte hacia los mercados.

Como semblanza y documento histórico de la vida llena de calamidades y vicisitudes por las que atravesó el refugiado espanol radicado en las colonias agrícolas, tres escritores republicanos dejan traslucir sus experiencias a través de las novelas que escribieron durante esos años, son ellos Mariano Viñueales con Blanquito y Eduardo Capo Bonnafous con Medina del Mar Caribe. Asimismo, Eduardo Granell, en La novela del indio Tupinamba, satiriza la preferencia de las autoridades dominicanas por el inmigrante agricultor. Al hacer referencia a la documentación exigida para fines de declaración frente a las autoridades de migración, Granell en un fragmento de su novela escribe a modo de parodia, lo siguiente:

«Lugar de nacimiento:
nombre de la madre:
nombre del padre:
raza:
credo político:
prof esión:
diga si es labriego:
firme aquí:

labriego labriego labriego labriego labriego labriego labriego labriego" (12)

(12) Llorens [10], pág. 132. 
Esta satirización de la realidad imperante para los inmigrantes republicanos de ese entonces, encuentra explicación en el marcado interés del gobierno dominicano por atraer agricultores. Desde finales de la década del 30 e inicios del 40, Trujillo había dado paso a un plan tendiente a incrementar el volumen de la producción agrícola en terrenos marginales, con el objetivo de suplir la demanda de alimentos y materias primas por parte del mercado interior, así como aumentar la producción de uno que otro rubro de exportación. Y, por qué negarlo, también existía el deseo implícito de blanquear la población rural.

El sistema de colonato bajo el cual fueron asentados estos refugiados españoles en diversos puntos del país, propendía en orden de importancia hacia la producción de hortalizas (tomate, ají, ajo y cebolla), maní para la fabricación de aceites, arroz, papas, etc. Se implantó mediante la explotación de pequeñas parcelas, cuya propiedad no era plena, sino tras un determinado número de años de usufructo continuo, no menor a los cinco años. Esta inmigración tuvo lugar al amparo de la Ley $\mathrm{n}^{\mathrm{0}} .77 \mathrm{del}$ 2 de diciembre de 1924, aunque no hubo una total correspondencia entre lo jurídico y la realidad. Mediante esta ley se declaraba de utilidad pública la colonización de la frontera, se estipulaba la entrega a cada familia de la suma de 110 pesos dominicanos y de un predio de 200 tareas; a lo que se debía agregar el pago de 30 pesos mensuales; instrumentos de trabajo ( 3 palas, 2 picos, 3 azadores, 5 machetes y 4 hachas) y una vivienda. Desde luego, tales ofrecimientos no se cumplieron cabalmente.

\section{ColONIAS AGRÍCOLAS DE ESPAÑOLES EN 1955}

Es a mediados de la década del cincuenta cuando la llamada "emigración dirigida" de agricultores españoles se"hizo realidad, a raíz del viaje de Trujillo a España, en octubre de 1954, y en particular a Valencia, donde admiró no sólo la fertilidad y el cuidado de la huerta valenciana, sino también la laboriosidad del campesinado en la producción del arroz. El gobierno dominicano, con el objetivo de atraer a una corriente de inmigrantes agricultores, ofreció suministrar, como aparece en el diario español ABC en enero de 1955, lo siguiente:

a cada cabeza de familia una casa para vivienda y una extensión de terreno que tendrá como mínimo 50 tareas y como máximo 
500, siendo 16 tareas equivalentes a una fanega valenciana. El mínimo y el máximo de las tierras a adjudicar responde al número de brazos que, además de la cabeza de familia cuente ésta, pudiendo incluso aumentarse ese máximo. Tanto las viviendas como las tierras, son completamente gratuitas, facilitándose asimismo, los aperos y enseres agricolas necesarios para el cultivo. Además de estar exentas de impuestos, las cosechas serán propiedad de los agricultores, que no podrán venderlas dentro o fuera del país. El compromiso es sin plazo fijo, pudiendo prolongar todo el tiempo que el agricultor lo desee y comprometiéndose el gobierno dominicano a facilitar el pasaje de retorno a España, en el caso de rescindir el contrado por cualquier motivo.

Con el interés de llevar a cabo este programa inmigratorio, el Estado dominicano compró el barco transatlántico denominado "España»; que, junto a otras embarcaciones italianas ("Auriza» y "Ascania") hicieron posible el paso de un continente a otro de estos bravíos hombres y mujeres del campo español.

Para alcanzar la traída de un número superior a los 4.000 inmigrantes, el Estado dominicano contrató los servicios del señor Manuel Fernández Cámara, como encargado del reclutamiento y de la organización de los viajes, o "gancho" - tal y como se le denominaba a quien ejercía tales funciones-. Sin embargo desde mediados de 1955 las autoridades españolas criticaban este sistema de reclutamiento, estimulando para que fuese hecho, más bien, a través de los sindicatos, como vía para encauzar la emigración en mejores condiciones, evitando así el abuso de los intermediarios, al tiempo que se cumplieran los requisitos de la legislación vigente (13).

De acuerdo con testimonios of recidos por cuatro agricultores, que aún siguen laborando la tierra de Constanza, éstos tuvieron conocimiento de esta empresa a través del alcalde de sus respectivos lugares de origen, a quienes Fernández Cámara visitara para informarle de su interés de traer a Santo Domingo a centenares de hombres y mujeres, con el propósito de que se establecieran en los campos dominicanos.

Para lograr hacer el viaje, los emigrantes debían pagar hasta 5.000 pesetas, por concepto de los trámites legales a cargo de las propias agencias de viajes. Esto dio lugar, igualmente, a fuertes críticas, al extremo de perseguir y de multar con altas sumas de

(13) MEAE, leg. Reg. 5.667, exps. 2 y 4. 
dinero a quienes se beneficiasen de tales servicios, por considerárseles como delitos.

Ahora bien, para el gobierno dominicano este proyecto inmigratorio repondía no sólo a un interés poblacional y étnico-racial -puesto de manifiesto mediante la disposición del pago de 250 pesos y la entrega del ajuar al español soltero que se casara con una nativa-, sino que además de expresar solidaridad y simpatías hacia el régimen franquista, el país se vería beneficiado por el incremento de la producción agrícola, alcanzado por un mayor rendimiento productivo y mejoras tecnológicas. Además, el proceso de industrialización sustitutivo de importaciones que Trujillo venía impulsando en esa década, principalmente en la ciudad de Santo Domingo, encontraba un apoyo en estas colonias agrícolas, pues ellas debían suministrar, por un lado, los bienes alimenticios para garantizar la reproducción de la fuerza de trabajo incorporada en las industrias y en la construcción, y, por el otro lado, aunque en menor medida, insumos industriales, como es el caso de la producción de maní, en la colonia de Baoba del Piñal, en la región norte del país. Este proyecto tenía una importancia estratégica para el régimen trujillista, tal y como se desprende de la correspondencia consular entre el Embajador de España y el Ministro de Asuntos Exteriores en Madrid, fechada en mayo de 1955, pues en la misma se informa que las autoridades oficiales dominicanas para llevar a cabo esta inmigración y colonización de españoles habían solicitado ayuda financiera al gobierno norteamericano, mediante el Encargado de Negocios de los Estados Unidos, y quien se lo hizo saber al diplomático español, en términos muy favorables (14).

Sin embargo, mientras que esta inmigración respondía a un programa organizado o más bien dirigido, en España esta emigración colonizadora llevada a cabo por estos agricultores españoles, tuvo un carácter privado, ya que se hizo sin intervención estatal, cuestión que dio lugar, en cierta medida, a que estos inmigrantes se vieran afectados' por innumerables dificultades económicas y de adaptación al medio, una vez instalados en tierras dominicanas. Entre 1955 y 1956 llegaron al país 4,131 emigrantes, principalmente integrados por hombres solteros, procedentes de diversas provincias de España, que fueron asentados en las localidades rurales de Baoba del Piñal (Cabrera), Constanza, Jarabacoa, Azua, San Juan, Pepillo Salcedo, Nagüa y Monte Christi.

(14) MEAE, leg. Reg. 5.667, exp. 3. 
TABLA 2. COLONIAS AGRÍCOLAS DE INMIGRANTES ESPAÑOLES 1955

\begin{tabular}{|c|c|c|}
\hline Expediciones & Población & Localización Asentamientos \\
\hline Enero & 755 & Baoba del Pinal 1 \\
\hline Junio & 764 & $\begin{array}{l}\text { Baoba del Pinal (614) } \\
\text { Constanza (150) }\end{array}$ \\
\hline Septiembre & 409 & $\begin{array}{l}\text { Baoba del Pinal } \\
\text { San Juan de la Maguana } 2\end{array}$ \\
\hline Octubre & 350 & $?$ \\
\hline Noviembre & 1.170 & $\begin{array}{l}\text { Baoba del Pinal ( } 650) \\
\text { San Juan de la Maguana Azua }{ }^{3} \text {. }\end{array}$ \\
\hline
\end{tabular}

1 Las Payitas, Ochoa, La Estrada, Vista Linda, San Rafael, Doña María.

2 Vallejuelo (Antigua Provincia Benefactor), Guanito.

3 Azua fue clausurada porque al hacer la entrega de las tierras, éstas ya habian sido vendidas a una gran compañia que implantó cultivos de Henequen, en grandes extensiones.

El primer contingente de agricultores que arribó en enero de 1955, y que había zarpado del puerto de Valencia, ascendía a 756 inmigrantes, entre los que se encontraban alrededor de 30 mujeres. Estaba integrado por personas que procedían de diferentes lugares de las provincias de Valencia y Burgos (Sedaví, Silla, Albal, Algemesí y otras), así como alrededor de 200 canarios que habían embarcado en el puerto de Santa Cruz de Tenerife, donde hicieron escala.

El segundo grupo de 763 inmigrantes, en su mayoría solteros, eran oriundos de La Coruña, Santa Cruz de Tenerife y de Las Palmas. Hacia finales de 1955 y principios de 1956, arribaron al país dos contingentes adicionales, uno de 1.170 y otro de 367 , que procedían en orden numérico de importancia de Lugo, Pontevedra, Orense, Alicante, Barcelona, Zamora, Soria y León. De acuerdo a las estadísticas españolas de la Dirección General de Trabajo, estos emigrantes salieron principalmente por los puertos de Vigo y de Cadiz (60\% y $24 \%$, respectivamente). Profesionalmente el $87 \%$ eran obreros agrícolas, seguidos por el grupo de las mujeres y los niños (15).

Para todos ha de resultar curioso conocer las razones que dieron lugar, en años recientes, a la salida de España de estos

(15) Boletín Estadistico de la Migración Transocéanica, Instituto Español de Emigración, Madrid. 
agricultores peninsulares. Tradicionalmente se hace hincapié en el carácter aventurero del español y en su interés de "hacer la América», pero mediante testimonios orales, estos mismos hombres y mujeres enfatizaron en el carácter perentorio de su emigración. Tal y como expresaron varios agricultores entrevistados, que en la actualidad han alcanzado excelentes condiciones productivas y, por consiguiente, buenos niveles de vida: «salimos de España porque había un momento crítico, luego de la guerra, España está bloqueada y había desempleo y el gobierno había dejado al pueblo a su libre albedrío y desde luego, no todos teníamos tierra, el hecho de saber que podíamos tenerla y que nos darían viviendas nos hacia pensar que tendríamos una mejoría». Una minoría nos manifestó, que por esta vía escapaban del régimen franquista.

\section{POBLACION ESPAÑOLA EN COLONIAS AGRICOLAS EN REPUBLICA DOMINICANA.

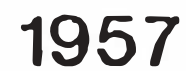

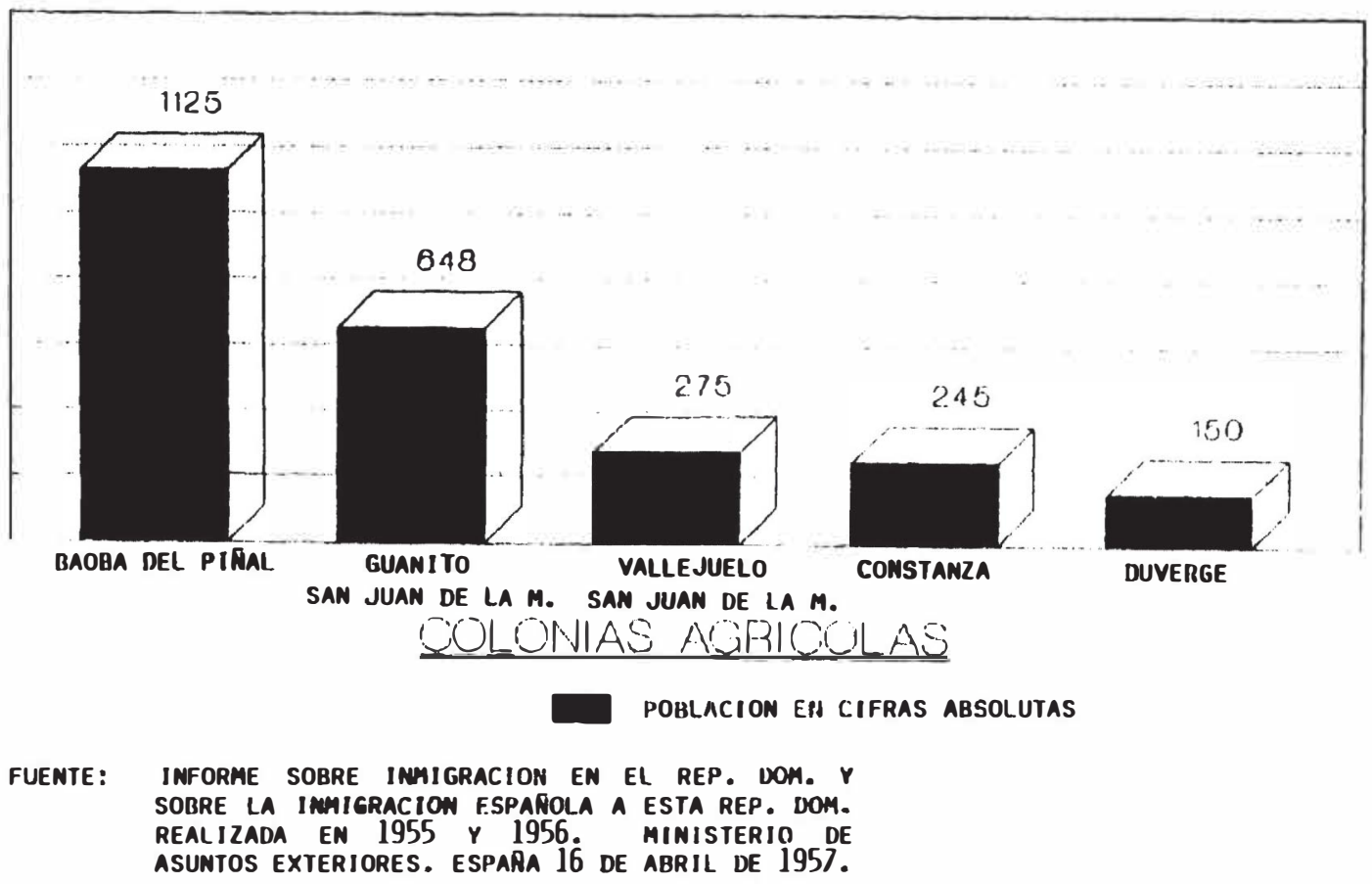




\section{VICISITUDES DE UNA EMPRESA COLONIZADORA}

Las primeras vicisitudes por las que atravesaron estos agricultores españoles y sus familias, tienen lugar desde la propia travesía, realidad que se constituyó en un condicionante para la conformación de agrupaciones regionales y de juntas directivas, que más tarde les permitirian gozar de una mayor capacidad de negociación para interpelar a las autoridades dominicanas, al tiempo de constituirse en medios para acceder a préstamos frente al Banco Agrícola.

Como anécdota, españoles entrevistados, entre los que llegaron en el primer grupo, nos han referido que el barco "España» se dirigió hacia el puerto de Sánchez en la Bahía de Samaná y, posteriormente, a Baoba del Piñal, pero que la embarcación en la que navegaban, debido a averías en las calderas, encayó y tuvo que ser remolcada. Una vez llevados a Baoba del Piñal, primer lugar de destino, estos hombres y mujeres sólo encontraron terrenos sin cultivar, llenos de malezas y con suelos áridos, donde sólo existían árboles de guayaba, teniendo que iniciar sus labores por el desmonte de los terrenos, y sólo al cabo de un tiempo lograron cosechar mani.

Al llegar a Baoba, crearon varios poblados, entre los que se destacan, San Rafael y Payita, que a pesar de carecer de agua corriente y de electricidad, fueron instalados allí, de manera aislada, en pequeñas viviendas - con paredes de cemento y techos de zinc, y compuestas de una sala y un dormitorio-, alojando hasta seis personas en una de ellas cuando era ocupada por solteros, o en caso contrario por una familia. En el área de la cocina, situada junto a la vivienda, el Estado dominicano apenas las dotaba de un anafe de hierro, dos pailas y varias cucharas.

Como fruto de las quejas de los primeros colonos y hasta de la inconformidad mostrada por las propias autoridades diplomáticas españolas, los inmigrantes ubicados en Constanza fueron asentados en viviendas con mejores condiciones, ya que además de que eran construídas en poblados que previamente contaban con agua corriente y luz eléctrica, eran de mayor tamaño al contar con tres dormitorios.

Otra de las dificultades por la que atravesaron estos inmigrantes, tal y como nos lo han puesto de relieve en sus testimonios, se debió a que les fueron entregadas herramientas desconocidas por el campesino español, tales como el machete y el colín, 
mediante las cuales tuvieron que preparar los suelos. A ello se agregaría el reducido jornal diario, de apenas 60 centavos.

Entre los españoles que lograron superar los obstáculos que imponía el propio clima, se destacan los que procedían de las islas Canarias y de Valencia, que alcanzaron a desarrollar la producción, principalmente de maní, en parcelas de aproximadamente 10 a 30 tareas, generalmente situadas detrás de las viviendas. Posteriormente, los oriundos de Burgos y de Galicia que llegaron en las siguientes expediciones de agricultores, solicitaron ser instalados en zonas mas templadas, como es el caso de la colonia de Constanza, donde desarrollaron con el tiempo la siembra de la papa y otros cultivos propios de climas fríos.

Bajo tales condiciones, estos asentamientos agrícolas se caracterizaban por innúmeras limitaciones y deficiencias, tal y como se señala en un informe elaborado por un representante del gobierno español, en 1956, para rendir cuentas del estado y situación en que se encontraban estos colonos agrícolas, el cual se podría resumir en los siguientes aspectos:

$1^{\mathrm{o}}$ La falta de un convenio de emigración previo que contuviese una legislación y reglamentaciones necesarias para garantizar el funcionamiento de estas empresas colonizadoras de agricultores.

2o Ausencia de un previo acondicionamiento de la zona a colonizar.

$3^{\text {o }}$ Inescrupuloso reclutamiento de inmigrantes, caracterizado por una incorporación incontralada e indiscriminada de personas.

4o Ausencia de una eficiente colaboración técnica para la explotación de los suelos por parte del gobierno dominicano.

5o Forzada ociosidad de los inmigrantes durante los primeros meses, debido a la carencia de recursos materiales of recidos por las autoridades dominicanas (16).

Frente a este cúmulo de vicisitudes la mayor parte de estos inmigrantes retornaron a España, y otros progresivamente se trasladaron hacia las principales ciudades del país. El resto, cuyo número no supera a los cincuenta, hasta la fecha se encuentran

(16) MEAE, leg. Reg. 5.667, exp. 3. 
laborando los suelos dominicanos de Constanza, Nagüa y San Juan de la Maguana entre otras localidades rurales.

\section{CONVENIO DE EMIGRACIÓN HISPANO-DOMINICANO}

A pesar que el proceso de asentamiento agrícola de inmigrantes españoles se inició a principios de 1955, no es hasta el mes de febrero de 1956 que los gobiernos de España y República Dominicana firmaron un convenio, por iniciativa de las autoridades dominicanas, "encaminado a orientar y proteger el establecimiento de los españoles para contribuir con sus naturales al fomento de su riqueza económica dentro de la comunidad de idioma, religión, cultura y tradiciones de ambos Estados» (17). Este convenio de emigración encontró su validación por parte de las autoridades dominicanas, fundamentándose en el aspecto político-ideológico en lo que se denominó hispanidad trascendentah tal y como lo expresara en ese entonces el canciller Lic. Porfirio Herrera Báez, al decir: «...que se manifiesta en los ideales comunes que persigue nuestra raza, en las actitudes espontáneas que asumimos ante determinadas situaciones en que está involucrada la Madre Patria y hasta en ese latir inusitado de nuestros corazones frente a todo lo bello, apasionado y dramático de España, sobre todo, este instrumento tiene un alto sentido de recuperación histórica» (18).

Este convenio de emigración hispano-dominicano, en líneas generales, estipulaba lo siguiente:

1) La emigración deberá contar con la orientación y organización de ambos gobiernos.

2) Permiso para el establecimiento de españoles, solos o con sus familias, en suelo dominicano.

3) El número de los casados no debe exceder a un tercio de la totalidad de la lista definitiva de emigrantes.

4) Los gastos de estas operaciones correrán por cuenta del gobierno dominicano, quien les ofrecerá un visado de permanencia.

5) Los emigrantes podrán llevar consigo las ropas y efectos

(17) El Caribe, 12 de febrero, 1956.

(18) Idem, ibidem. 
de uso personal, así como sus herramientas o aperos de labranza, con exención de derechos de aduanas. En caso de que no las posean, el gobierno español suministrará dichas herramientas, cuyo valor será, reembolsado luego por el gobierno dominicano.

6) Para evitar irregularidades y abusos en el trato a los emigrantes, cada expedición deberá contar con un inspector de emigración español, quien rendirá un informe al finalizar la travesía y hasta llegar al lugar del asentamiento.

7) Se asegurará el derecho y la posibilidad de transferir sus ahorros a España, bajo las condiciones previstas por la legislación dominicana en materia de divisas.

8) Los emigrantes españoles podrán traer a sus familiares, con recursos propios, mediante carta de llamada a las autoridades diplomáticas españolas, para suministrar pasaportes y a las autoridades dominicanas para el visado.

9) El gobierno dominicano se compromete a facilitar a los emigrantes españoles asistencia religiosa, médica y escolar.

En este último artículo, aunque finalmente fue aprobado, hubo disparidad de criterios entre las autoridades de ambas naciones, pues la propuesta del Estado español disponía que cada expedición y, por consiguiente, cada colonia agrícola contase con un sacerdote. Sin embargo, el gobierno dominicano en un principio hizo resistencia, tal vez como expresión de la pugna que finalmente tuvo lugar entre Trujillo y las autoridades eclesiásticas, acrecentada en las postrimerías de su régimen dictatorial (19).

\section{LOS AGRICULTORES ESPAÑOLES DESPUÉS DE TRUJILlO}

Si bien estos agricultores españoles tuvieron que enfrentarse a innumerables tropiezos, incluso provocando el retorno a España de un gran número de ellos, es a raíz de la muerte de Trujillo y caída de la dictadura cuando estas dificultades se acentuaron.

Uno de los mecanismos de acumulación originaria de capitales de la que se valió el modelo trujillista para acaudalar las mayores fortunas del país, fue el despojo de las tierras al campesinado

(19) MEAE, leg. Reg. 5.667, exp. 3. 
por medios extraeconómicos, garantizados por la condición de dictador de este gobernante. Bajo tales condiciones, la ilegalidad estuvo presente en muchas de las medidas gubernamentales. Como por ejemplo, las tierras que fueron entregadas a los colonos españoles carecían de sus correspondientes títuios de propiedad, figurando en la Oficina Nacional de Catastro bajo el nombre de sus antiguos propietarios. Esta realidad, a raíz de la abrupta muerte del gobernante, generó numerosos conflictos entre los campesinos nativos y los agricultores hispanos. Conflictos comprensibles a la luz de las características coyunturales propias de un periodo postdictatorial, donde primó la confusión y la generalizada voluntad de recuperar los derechos negados durante tres décadas, por parte del campesinado dominicano.

Así las cosas, algunos campesinos oriundos de las localidades y parajes donde se habían establecido estas colonias agrícolas, invadieron violentamente las tierras de estos productores españoles, desconociéndoles todo tipo de derecho jurídico, por lo que tiempo después las autoridades dominicanas se vieron obligadas a pagar una indemnización de 2100 pesos a cada uno de los colonos españoles afectados. De este modo, un gran número de españoles que se habían mantenido cultivando las tierras, tuvieron que abandonar sus parcelas, viéndose en la necesidad de comprar otras, donde hasta la fecha han desarrollado exitosas empresas agrícolas.

\section{APORTACIÓN}

De manera especial, este trabajo pretende destacar también la incidencia de estos colonos españoles en el presente sistema agrícola dominicano. Como bien ha señalado Manuel García Arévalo "estos inmigrantes establecidos en el campo han realizado aportes significativos en el cultivo de varios renglones agrícolas, tales como el arroz, la papa, la cebolla y el ajo, la horticultura y la floricultura, entre los que cabe mencionar al agricultor valenciano José Pascual Roselló Campins, gracias a la siembra de ajo y cebolla en terrazas y al empleo de otras innovaciones tecnológicas. En este sentido, continuarian la labor que desde principios de siglo había desarrollado una pequeña colonia hispánica en las lomas de Barahona y en otras provincias de la zona Norte, con el cultivo de café. Más recientemente, los españoles seguirían contribuyendo con la agricultura dominicana, particularmente con 
la producción a gran escala para fines industriales..., con el cultivo del tomate" (20).

Si desglosamos los aportes de estos hombres a la agricultura dominicana, veremos que los inmigrantes españoles que se establecieron en Constanza - hoy en día considerada como zona modelo de la producción agrícola y durante muchos años como la colonia más exitosa-, han ido desarrollando, mediante la prueba del ensayo y el error, una producción agrícola intensiva de gran rentabilidad. En los primeros tiempos se vieron precisados a acondicionar los pantanosos terrenos de las zonas donde fueron asentados, a través del sistema de drenaje y de regío, a diferencia del campesino nativo de ese entonces, que sólo sabía producir en terrenos de secanos.

En cuanto a las técnicas para la siembra, mientras en el país tradicionalmente se seleccionan los desperdicios de las cosechas como semillas de las próximas siembras, los hispanos han escogido sus mejores productos, obteniendo de manera creciente una mejor calidad de su producción agrícola. Además, como una innovación tecnológica en la fase de la siembra, han implementado la producción en terrazas, aprovechando los terrenos en laderas e introduciendo en el país el cultivo de frutales exóticos al medio dominicano, tales como la manzana, la ciruela, el albaricoque, la frambuesa y el kiwi.

Otra técnica de siembra desarrollada por estos agricultores fue el surco, con una inclinación de los suelos de un 5\%, lo que les ha garantizado excelentes rendimientos en la producción de la papa y del ajo. Por otro lado, innovaron en los métodos para el abono, utilizando por primera vez en el agro dominicano el estiércol de la gallina, conocido con el nombre de gallinaza.

En cuanto a los equipos agrícolas utilizados, inicialmente, estos agricultores españoles frente al incumplimiento de las autoridades dominicanas de entregarles los instrumentos de labranza prometidos, se vieron en la necesidad de fabricar sus propios arados, construyéndolos de manera rústica y similares a los romanos. Sin embargo, hoy en día, han alcanzado tal desarrollo que han sido los primeros en introducir en el país la máquina para la recolección de papas.

(20) Manuel García Areval.o, "La inmigración española en República Dominicana: la presencia gallega". I Jornadas sobre la Presencia Española en América: aportación gallega. Pazo de Mariñán, 1987. 


\section{BALANCE}

Es obvio que, con el transcurrir del tiempo, estamos en mejores condiciones para pasar balance de un proceso inmigratorio y de colonización agrícola tan significativo como ha sido el constituido por este nutrido grupo de humildes y laboriosos hombres y mujeres del campo español. A pesar de que algunos se lamentan de haber salido de su lar natal y de haberse alejado de sus familias de origen, se sienten satisfechos de haber vencido con trabajo y tesón los múltiples obstáculos con los que se encontraron a su llegada a suelo dominicano, para hoy contar con fincas bajo excelentes condiciones productivas y ofreciendo a sus hijos lo mejor de sí y de sus condiciones, procurándoles incluso una formación superior en reconocidas universidades norteamericanas y españolas.

Estos inmigrantes españoles, hoy exitosos empresarios agrícolas, han aportado económica y socialmente al país al incrementar la generación de empleos y el nivel de ingresos de las comunidades donde se han establecido, así como por su incidencia en la elevación y diversificación agrícola, con el uso de una tecnología mas avanzada.

A modo de colofón, podríamos decir que estos inmigrantes han dejado una invaluable huella, no sólo en la tierra sino en el estilo de vida de las comunidades donde se radicaron. Para tal afirmación nos apoyamos en el testimonio que nos of reciera un campesino criollo, quien nos dijo: «...los españoles, tanto los que vinieron solos como los que llegaron con sus familias, nos han ofrecido un ejemplo con su trayectoria de vida y sus buenas costumbres, así como por la laboriosidad de sus mujeres, quienes también han enseñado a las jóvenes de estos lugares a hacer manualidades propias de las artesanías, mientras que los hombres hemos aprendido a trabajar incansablemente y a aprovechar mejor las tierras". 